\title{
Impacts of Climate Shock Response Measures on Poverty Vulnerability of Farmer Households in the Mekong River Delta
}

\author{
TRAN DAI NGHIA \\ Institute of Policy and Strategy for Agriculture \& Rural Development - tran.nghiadai99@gmail.com \\ LE TRONG HAI \\ Institute of Policy and Strategy for Agriculture \& Rural Development - lehai_ipsard@yahoo.com \\ DOAN MINH THU \\ Institute of Policy and Strategy for Agriculture \& Rural Development - doanthu85@gmail.com \\ DINH PHI HO \\ University of Economics HCMC - dinhphiho@gmail.com \\ This research was funded by the National Fund for Scientific and Technology Development \\ (NAFOSTED) in the research No II6.1-2012.14.
}

\section{ARTICLE INFO ABSTRACT}

Article history:

Received:

Feb. 262016

Received in revised form:

Mar. 152016

Accepted:

Jun. 202016

Keywords:

climate change, poverty, vulnerability, farmer, income reduction.
The analysis of this study is based on the inherited results using the panel data of climate shocks and risks faced by farmers in 12 preventative provinces of the seven ecological regions of Vietnam as surveyed by IPSARD (2013) and the data collected from the in-depth studies with 330 farmer households sampled from six selected provinces that represent five sub-ecological areas of Mekong River Delta. The response probability models are employed to determine the impacts of weather risks on incomes of the farmer households as well as the effects of applying several climate change response measures on poverty vulnerability of the farmers. As shown by the analytical results, the poor household group is most impacted by the natural risks, which in turn also affects the level of their poverty vulnerability. To mitigate the negative impacts of extreme weather events, farmers have proactively applied different responsive measures designed to improve their resilience to climate and natural risks, such as changing crop or animal varieties, changing farming patterns, and improving production infrastructures. These measures are found to have contributed significantly and effectively in preventing productivity decline and mitigating income losses and therefore the farmers' poverty vulnerability. 


\section{Introduction}

Vietnam has gained rapid economic growth and impressive achievements in poverty reduction over the past two decades. However, the development is now at risk of being seriously affected by the impacts of climate change (McElwee, 2010). A range of local and international researches has ranked Vietnam as one of the most severely affected countries by climate change's impacts (MONRE, 2010). World Bank (Technical report, 2008) has put Vietnam on the list of 12 countries that are most vulnerable to climate change.

Vietnam has quite varied terrain with three fourths of its area being upland and hilly (Vietnam Government, 2013). Hilly terrain with a long coastline and its location in the center of the tropical storms cause the country to be easily affected by sea level rise and extreme weather events such as floods, landslides, and heavy rain. Besides, since agriculture accounts for $21 \%$ of GDP (GSO, 2013) and 48.4\% of total workforce (GSO, 2012), climate change will also strongly influence several different aspects of farmers' lives such as income, livelihoods, poverty, the inequality of income, vulnerability, and health and nutrition. This research examines the impacts of some climate change response measures on poverty vulnerability of the farmer households.

\section{Theoretical bases and methodology}

\subsection{Literature review}

According to the National Strategy on Climate Change (2011), Vietnam is considered one of the countries severely affected by climate change, and the Mekong Delta is one of the three plains in the world being the most vulnerable due to sea level rise besides the Nile Delta (Egypt) and the Ganges Delta (Bangladesh). Strongly influenced by the climate change are many aspects of famers' lives such as income, likelihood, poverty, inequality income, vulnerability, health, nutrition, and so on.

So far numerous researches and studies on the impacts of climate change and farmers' responses to those impacts have been done, applying different approaches, methods, and instruments. From 2004 to 2011, a series of works on these were published in Vietnam. World Bank (2010) conducted a research with the focus on social dimensions of adaptation to climate change and the aims to: (i) identify social vulnerability and adaptive capacity in climate-change-affected regions of Vietnam and of vulnerable 
people; (ii) establish a dataset to analyze and provide advice for the overall EACC study on the role of social assessment to clarify the issues of vulnerability, adaptation, and economic costs. Some of the methods applied in the study such as community risk mapping, focus groups discussion, and key stakeholder and semi-structured interviews were suitable for the case study.

Poverty reduction is another issue that arouses concern over analyses of farmers' responses to climate change. Oxfam (2008), in his research in Ben Tre and Quang Tri provinces, recommended that poor women's and men's needs and interests must be at the heart of national and local research and policy planning on adaptation. The research methodology of this study is also appropriate for case studies.

In another project conducted by Few et al. (2006), they approached the climate change problem from a poverty reduction perspective besides further details on the following: (i) how and under which conditions can current disaster risk management practices help prepare for climate change; (ii) under which circumstances does climate change require changes in disaster risk management approaches; and (iii) what lessons can be learnt from the exercise that could inform wider adaptation policy. The paper used a series of recommendations, drawn from input to the Vietnam country study, feedback from country experts, and an international VARG workshop in Geneva, Switzerland. The authors, considering multi-hazard and cross-sector aspects, proposed several recommendations with an emphasis on a series of means which facilitate the connection of climate change and disaster control practices in association with poverty alleviation.

Moreover, several studies tend to focus on the climate change in agro-ecological regions of Vietnam. In his research Britta Heine (2009) gathered successful approaches and lessons to develop a guideline of adaptation to climate change in coastal areas of the Mekong River Delta. The study provided concepts and methods for planning and implementing farmer adaptation in three provinces (Soc Trang, Kien Giang, and Bac Lieu), and then put forward implications for better adaptation to the climate change in coastal areas such as focusing on mangroves and small-scale aquaculture in the mangrove forest areas.

Asian Disaster Preparedness Center (2003) demonstrated that poverty and lack of capacity to address climate change and variability would increase the risk of disaster to the Vietnamese population. On the other hand, the paper suggested better responses to 
climate change in the Mekong Delta such as crop diversification and aquaculture-based industrial ventures, which could provide capital for developing agro-industry and accelerate the industrialization process in the region. Gradually, large numbers of Mekong River Deltal workers will be shifted from high-risk coastal areas to other industries, and then free the land for managrove cultivation.

There is also a variety of international researches on effects of climate change on farmers and their responses in recent years. Lasco et al. (2011) pointed out its impacts on agriculture and lives of the farmers with small-scale production. In particular, not only do small-scale farmers suffer climate change impacts significantly on crop yields, crop diseases, livestock, and water pollution but they are also vulnerable to risk of climate change. The study cited previous researches and indicated that an "adaptation gap" might exist in case of insufficiently implemented adaptation strategies, and consequently, it results in increased levels of negative impacts of natural disasters in the world recently. The study answered the question of what practices small-scale farmers may adopt for their climate change adaptation. A series of solutions was mentioned, including: (i) changing variety; (ii) changing crops and livestock, and cultivation time; (iii) changing agricultural management; (iv) diversifying sources of incomes and economic activities; (v) implementing carbon emission trading schemes; and (vi) improving linkage with community organizations. This is an up-to-date study on farmers' responses to climate change, which, however, reflects a lack of a basic theory and quantitative models.

The World Bank and FAO (2011) reached a better understanding of the issues and options at the frontier of agricultural adaptation to climate change, identifying the impacts and adaptation strategies and practices and exploring approaches to mainstream climate change in development programs. Study results are summarized from the World Bank's conference results about mitigating the impacts of climate change and enhancing food security. Adaptation measures are urgently required to increase the overall flexibility of the agricultural systems against climate shocks and changing market demands. Possible adaptation solutions include: (i) modification of farming practices; (ii) diversification and development of new and more climate-induced stress resistant crop varieties; (iii) improved soil conservation and water resources management; (iv) supplementary and improved irrigation systems; (v) development of monitoring and early warning systems; (vi) better use of risk transfer mechanisms; and (vii) an enabling policy environment. 
Gbetibouo (2009), for the first time in his research pursuit, applied the "bottom-up" approach in order to find out farmers' responses to climate change. The database of this study was collected from 794 households in the Limpopo Basin of South Africa during 2004-2005. The study examined the level of farmers' awareness in accordance with the weather data collected by meteorological stations, as well as analyzed the farmers' responses to climate and weather changes. Using Heckman probit and multiple logit models, this research sought to examine the elements of adaptation to climate change. Its statistical analysis of climate data showed the year-by-year increase in temperature and change in rainfall. Despite being in line with the climate data reports, the results suggested that only about half of the farmers had adjusted their farming activities to respond to the climate change impacts. Lack of access to credit was a major factor that limited the adaptation. The results of the multiple choice logit and Heckman probit models emphasized that farmers' scale, farming experience, wealth, access to credit, access to water, the right to ownership, non-farm activities industrial, and agricultural extension approach are essential to improved adaptability. Based on such, it was proposed that the South African Government should design policies for better improvements in these factors.

\subsection{Analytical framework and methods}

The research was conducted on the ground of the following analytical framework.

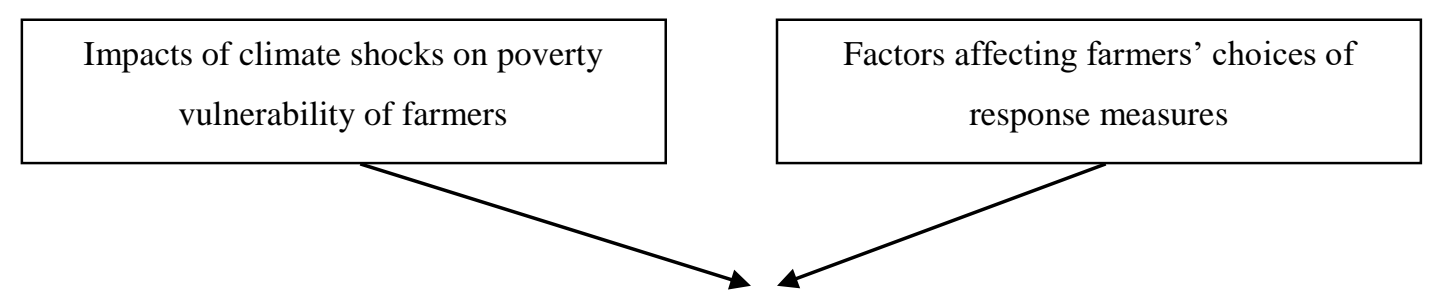

Response measures selected

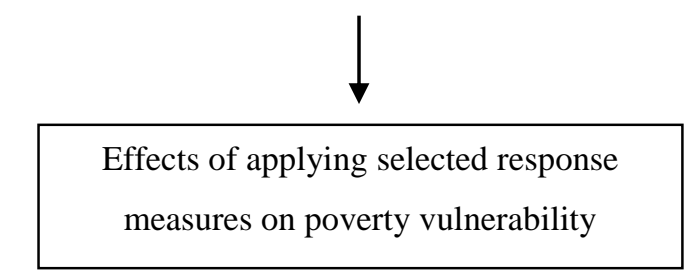

Figure 1. Analytical framework of the research 
The analysis was drawn from inherited results using the panel data of climate shocks and risks encountered by farmers in 12 preventative provinces of the seven ecological regions of Vietnam as surveyed by IPSARD (2013). The data were also collected from the in-depth studies with 330 farmer households sampled from six selected provinces that represent five sub-ecological areas of Mekong River Delta. These provinces are most affected by the climate change in Vietnam, and to estimate this, we adopt multistage cluster sampling technique (Ahmed, 2009). In order to control for data reliability and validity as well as measurement and sampling errors, we use a number of tests and measurements. After the data collection process, several tests are employed to ensure unbiased estimates. These tests include testing for normality of residuals using the One Sample Kolmogorov-Smirnov test. The results suggest that some variables do not conform to the assumption of the regression analysis such as normality of the data. The data that violate the normality assumption are then transformed with the use of natural logarithms (Sheskin, 2004). Outliers whose observations have large residuals are removed from the analysis whereby cases with studentized residuals greater than the absolute value of 2 are excluded (Shuwu, 2006). In this research, Hadi's (1992) method is used to identify outliers at the $5 \%$ level of significance (default in Stata. 12). The Variance Inflation Factor (VIF) procedure used to detect multicollinearity is preferred to the correlation coefficient method, which fails to yield conclusive results (Pindyck \& Rubinfield, 1981). If the VIF is greater than 10, then there is a potential multicollinearity problem (Neter et al., 1989). Following such, we accordingly detect no serious collinearity problem among the independent variables. The latter test for homogeneity is conducted using the Breusch-Pagan/Cook-Weisberg test for heteroskedasticity (Stata, 2007 ), and the null hypothesis of constant variances for residuals is accepted ( $p>0.000)$. The correction for heteroskedasticity involves standardizing variables (by dividing every variable by its standard deviation) as suggested by Varian (1984) and Kuosmanen et al. (2007) before the actual regression analysis can be done.

\section{Table 1}

Descriptive statistics of the surveyed households in Mekong River Delta

\begin{tabular}{lccccc}
\hline Variable & Obs. & Mean & Std. dev. & Min & Max \\
\hline Age of household head (year) & 330 & 53 & 12 & 28 & 92 \\
Schooling time (year) & 330 & 6.1 & 3.3 & 0.0 & 16.0
\end{tabular}




\begin{tabular}{|c|c|c|c|c|c|}
\hline Variable & Obs. & Mean & Std. dev. & Min & $\operatorname{Max}$ \\
\hline $\begin{array}{l}\text { Gender of household head (=1 if male; } \\
=0 \text { otherwise) }\end{array}$ & 330 & 0.8 & 0.34 & 0.0 & 1.0 \\
\hline $\begin{array}{l}\text { Occupation }(=1 \text { if full-time farmer, }= \\
0 \text { otherwise })\end{array}$ & 330 & 0.87 & 0.33 & 0.00 & 1.00 \\
\hline Affiliation* & 330 & 4.1 & 1.32 & 1.0 & 5.0 \\
\hline Family size ( persons) & 330 & 4 & 1 & 1 & 8 \\
\hline Agricultural land (ha) & 330 & 3.07 & 3.77 & 0.12 & 20.5 \\
\hline Rice cultivation area (ha) & 191 & 1.97 & 2.53 & 0.63 & 20.5 \\
\hline Shrimp farming area (ha) & 88 & 3.02 & 2.63 & 0.05 & 18.2 \\
\hline Fish farming area (ha) & 20 & 1.71 & 1.99 & 0.01 & 5.5 \\
\hline $\begin{array}{l}\text { Rice yield in winter-spring crop } \\
\text { (tone/ha) }\end{array}$ & 191 & 6.9 & 1.94 & 0.54 & 13.0 \\
\hline $\begin{array}{l}\text { Value of rice production (million } \\
\text { VND/HH/year) }\end{array}$ & 191 & 170.6 & 202.8 & 20 & 1074 \\
\hline $\begin{array}{l}\text { HH applied changing variety }(=1 \text { if } \\
\text { changed, }=0 \text { otherwise })\end{array}$ & 330 & 0.71 & 0.45 & 0 & 1 \\
\hline $\begin{array}{l}\mathrm{HH} \text { applied ICM (=1 if changed, =0 } \\
\text { otherwise) }\end{array}$ & 330 & 0.68 & 0.46 & 0 & 1 \\
\hline $\begin{array}{l}\mathrm{HH} \text { applied ICM (=1 if changed, }=0 \\
\text { otherwise) }\end{array}$ & 330 & 0.79 & 0.40 & 0 & 1 \\
\hline
\end{tabular}

Source: data retrieved from authors' calculations using the surveyed data in 2014.

*This variable is measured using Likert's scale (= 1 if not a member of any social/mass organization; $=2$ if a member of one organization, $=3$ if a member of two different organizations, $=4$ if a member of three different organizations, and $=5$ if a member of more than four different organizations).

The data in Table 1 show that rice cultivation is a main agricultural production in the studied area, and it is followed by shrimp and fish (Tra fish) production. The farmers interviewed are experienced ones aged 53 on average. Most of the household heads are male, whose education levels are quite low (average of 6.1 years of schooling). Farmers quite proactively applied different climate risk response measures (average of all three responding measures of $0.68-0.79$ in the scale of 1 ). 
2.2.1. Assessing effects of climate change on productivity, poverty situation, and social differentiation

The economic model to identify correlation between effects of climate change on productivity, income, and poverty situation, is given by:

$$
y_{i}=a_{0}+a_{1} X_{1 i}+a_{2} X_{2 i}+a_{3} X_{3 i}+a_{4} X_{4 i}+u_{i}
$$

where $\mathrm{Y}_{\mathrm{i}}$ is the dependent variable, including income, productivity (yield), and poverty; $\mathrm{X}_{1 \mathrm{i}}, \mathrm{X}_{2 \mathrm{i}}, \mathrm{X}_{3 \mathrm{i}}$, and $\mathrm{X}_{4 \mathrm{i}}$ are vectors of the explained variable to represent: (i) observable effects of climate change; (ii) observable household characteristics; (iii) observable socio-economic characteristics of households; and (iv) observable local characteristics; $u$ is random with mean value equal to zero and variance equal to $\delta^{2}$; and $i$ is the ith observation.

The main steps to assess the impacts of climate change on social differentiation among farmers are as follows:

Step 1: Identify required measures of inequality of income index, including Gini index and Theil index and top-down rates of 10\%-20\%

Step 2: Calculate the inequality coefficient based on household survey data

Step 3: Identify scenarios in which impacts of climate change on famers' poverty vulnerability are estimated in monetary value, and calculate inequality coefficients of these scenarios

Step 4: Compare inequality coefficients before and after the "climate change impact"

\subsubsection{Assessing poverty vulnerability}

The household data were surveyed by Institute of Labour Science and Social Affairs (ILSSA) and Institute of Policy and Strategy for Agriculture and Rural Development (IPSARD) funded by DANIDA from 2006 to 2012. This survey was further in-depth studies of selected issues on Vietnam household living standards conducted by General Statistics Office of Vietnam in 12 provinces ${ }^{1}$. In particular, the survey data provided information on shocks and risk of farmers. The possibility that a farmer's consumption level (income) fell below a certain level due to shocks caused by climate change or extreme weather phenomena was estimated as an alternative approach for measuring poverty vulnerability.

According to Chaudhuri et al. (2002), the random process creating the consumption of a household is defined by: 


$$
\ln C_{h}=X_{h} \beta+e_{h}
$$

where $C_{h}$ is the consumption per capita, $X_{h}$ represents a group of household's characteristics (household size, location, educational level of household head, etc.) and climate shocks (drought, floods, hail, and salinity intrusion), $\beta$ is the parameter vector, and $e_{h}$ is random error with its mean of zero and followed normal distribution.

The logarithm of the expected consumption and variance of the logarithm of the household's income reduction $h$ can be estimated using estimated values of $\beta$ and $\theta$ as below:

$$
\begin{aligned}
& \hat{E}\left[\operatorname{lnDinc}_{h} \mid X_{h}\right]=X_{h} \hat{\beta} \\
& \widehat{V}\left[\operatorname{lnDinc}{ }_{h} \mid X_{h}=\sigma_{e, h}^{\wedge}=X_{h} \theta^{\wedge}\right]
\end{aligned}
$$

The consumption is assumed to have a normal distribution $\log \left(\ln \operatorname{Din} C_{h}\right)$. We estimate the probability that the household with characteristic $X_{h}$ is a poor one if (.) $\Phi$ shows the cumulative probability density in normal conditions, which is determined by:

$$
\widehat{V_{h}}=\widehat{P r}\left(\ln C_{h}<\ln z \mid X_{h}\right)=\Phi\left(\left(\ln z-X h \beta^{\wedge}\right) / \sqrt{ }\left(X h \theta^{\wedge}\right)\right)
$$

in which $\ln Z$ is the log of the minimum income, and if the household's income is lower than that level, then it could be considered vulnerable.

2.2.3. Analyzing the effects of applying different response measures on poverty vulrability

The results of analyzing the impacts of climate change (extreme weather events) on farmers' income and poverty vulnerability and those of analyzing the effects of adopting different climate change response measures on mitigating production decline and income losses are then incorporated into Eq. 1 to predict the impacts of climate change on farmers' income by 2030 under different climate change scenarios and also to decide on the fundamentals of farmers' proactively taking climate change response measures in the Mekong River Delta.

The 330 farmer households chosen to be surveyed represent those in the Mekong River Delta, selected from the six provinces of five sub-ecological regions.

Selection of the surveyed farmers for the in-depth studies is based on the multistage cluster sampling technique ${ }^{2}$.The provinces selected include: (i) the alluvian area along and between the Tien and Hau Rivers (An Giang and Can Tho provinces); (ii) Long 
Xuyen quadrangle (Kien Giang province); (iii) Plain of reeds (Long An province); (iv) Coastal belt areas (Ben Tre province); and (v) Ca Mau peninsula (Soc Trang province).

\section{Results and discussion}

\subsection{Impacts of climate risks (climate change) on income and poverty vulnerability of farmer households}

Table 2 shows that although the number of households experiencing risks falls, the percentage of the households who experienced income reduction increases due to the impacts of extreme weather events is revealed in some areas, becoming more serious than before. The income losses caused by climate risks account for about $50 \%$ of total income losses caused by all types of risks faced by the farmer households. Thus, the measures aiming at strengthening coping capacity during extreme weather events will significantly contribute to mitigate their negative impacts on farmers' income.

\section{Table 2}

Income loss proportion by risks

\begin{tabular}{lllll}
\hline & 2006 & 2008 & 2010 & 2012 \\
\hline Total losses in income & $60 \%$ & $25 \%$ & $12 \%$ & $15 \%$ \\
Income group 1* & $89 \%$ & $36 \%$ & $16 \%$ & $19 \%$ \\
Income group2 & $45 \%$ & $22 \%$ & $11 \%$ & $17 \%$ \\
Income group3 & $34 \%$ & $16 \%$ & $9 \%$ & $11 \%$ \\
Damage rate by risks: & & & & \\
Natural disasters & $50 \%$ & $68 \%$ & $48 \%$ & 30.9 \\
Floods, typhoons, v.v. & $24 \%$ & $34 \%$ & $20 \%$ & 8.6 \\
Diseases & $26 \%$ & $35 \%$ & $28 \%$ & 13.4 \\
\hline
\end{tabular}

Source: data analyzed from the survey results of CAP, CIEM, ILSSA, 2013

Notes: samples are only households affected by risks.

*Income groups 1, 2, and 3 denote low income, average income, and high income households respectively.

The results of Table 3 indicate that the low income group (Group 1) has the highest percentage of income loss; therefore, households in the poorest group become more 
vulnerable and easy to return to poverty if they are exposed to the risks and incur income losses.

\section{Table 3}

Fixed effects on the impact of income risks on household's assets

\begin{tabular}{l|cccc}
\hline Risks considered & $(1)$ & $(2)$ & $(3)$ & $(4)$ \\
\hline Income risks & $-0.153^{* * *}$ & & \\
& $(0.000)$ & & \\
External risks & & $-0.092^{*}$ & & \\
& & $(0.087)$ & & \\
External risks: natural & & & -0.027 & -0.028 \\
& & & $(.563)$ & $(0.351)$ \\
External risks: economic & & $-0.188^{*}$ & $-0.189 *$ \\
& & & $(0.081)$ & $(0.067)$ \\
\hline
\end{tabular}

Source: analysed from the survey's result of CAP, CIEM, ILSSA, 2013

Notes: Standard errors are grouped according to the recorded household level in parentheses (.). ***: The level of significance at $1 \%, * *$ : the level of significance at $5 \%, *$ : the level of significance at $10 \%$. Column (1): Negative impact on accumulation of the total of current assets. Column (2): Negative impact on current asset value. Column (3): The reduction of the total of current asset value overtime. Column (4): Impact on current asset volume.

3.2. Effects of adopting different climate change response measures on poverty vulnerability of the farmers

The analytical results obtained from linear probability model suggest that climate change and extreme weather events lead to reduced income and thus affect the accumulation of the total household's current assets and increase poverty vulnerability of households. However, climate risks have no statistically significant effect on the reduction of the total current assets over time or influence on the current asset volume. The analytical results of the impacts of climate change response measures adopted by farmers as represented in Table 4 show that for rice production in Mekong River Delta, changing rice varieties toward having shorter duration and better disease tolerance or resistance (Column 1) and changing crop patterns to avoid early draught or late flooding (Column 2) in order to minimize the impacts of flooding and salinization (caused by long draught condition) are two measures that have statistically significant contribution 
in mitigating income losses due to reduction in rice productivity. Meanwhile, for corn production, only changing crop patterns has significant impact on mitigating the income losses resulting from extreme weather events. Changing crop varieties can contribute to minimizing income losses in rice production by more than $18 \%$ (coefficient of -0.183 ), and changing crop patterns can mitigate income loss by about $4 \%$ in rice production and $7 \%$ in corn production. Different climate change response measures have no statistically significant effects on mitigating climate change impacts in fruit tree production. Given livestock and fisheries, the measures that produce statistically significant effects on mitigating loss involve adjusting stocking time and reinforced embankments and drainage system in fish and shrimp farming. For pig and cattle raising, their effects are not clear. The adjustment of stocking time based on early harvesting in the areas close to rivers and coastal areas before the flooding season can mitigate by up to $17 \%$ of income losses caused by extreme weather events in fish farming and $9 \%$ of those in shrimp farming.

Thus, proactive measures to respond to climate change such as changes of crop structure and animal varieties toward more resilience to extreme weather events and diseases as well as changes of crop patterns are suggested to make significant contribution to (or have statistically significant effects on) reduced income losses and therefore poverty vulnerability of farmer households, who have been facing with negative climate change impacts in their production.

\section{Table 4}

Effects of selected adaptation measures against reducing income losses caused by extreme weather phenomena in agricultural production

\begin{tabular}{lcccc}
\hline $\begin{array}{c}\text { Income reduction } \\
\text { caused by extreme } \\
\text { weather events } \\
(\text { Lndinc)* }\end{array}$ & \multicolumn{3}{c}{$\begin{array}{c}\text { Coefficients reflecting the effect of the adaptation measures adopted } \\
\text { to cope with extreme weather events }\end{array}$} \\
\cline { 2 - 5 } & M1 & M2 & M3 & M4 \\
\hline & $-0.183^{* * *}$ & $-0.036^{*}$ & -0.132 \\
Rice production & $(0.001)$ & $(0.0571)$ & -0.007 & \\
Corn production & -0.051 & $-0.072^{*}$ & & 0.214 \\
Fruit tree plantation & 0.002 & $-0.0693)$ & 0.071 & -0.008
\end{tabular}




\begin{tabular}{lcccc}
\hline $\begin{array}{c}\text { Income reduction } \\
\text { caused by extreme } \\
\text { weather events } \\
\text { (Lndinc)* }\end{array}$ & \multicolumn{3}{c}{$\begin{array}{c}\text { Coefficients reflecting the effect of the adaptation measures adopted } \\
\text { to cope with extreme weather events }\end{array}$} \\
\cline { 2 - 5 } & 0.031 & M2 & M3 & M4 \\
\hline Pig raising & 0.011 & - & -0.003 & 0.214 \\
Cattle production & 0.007 & $-0.172^{* *}$ & 0.031 & 0.017 \\
& & $(0.0452)$ & 0.009 & 0.017 \\
Fish farming & & $-0.091 * *$ & $-0.061 *$ & \\
& 0.217 & $(0.0718)$ & $(0.0584)$ & 0.038 \\
\hline
\end{tabular}

Source: results of the survey conducted in six provinces of Mekong River Delta, 2014

Notes: Lndinc is the natural logarithm of the decreases in income in agricultural production activities due to impacts of extreme weather (thousand VND/ha/year).

$*, * *$, and $* * *$ denote the levels of statistical significance of $10 \%, 5 \%$, and $1 \%$ respectively.

M1 (adaptation measure 1): using crop/animal varieties with better tolerance/resistance/resilience capacity when exposed to the extreme weather

M2 (adaptation measure 2): changing crop/animal patterns (earlier or later) to ease or escape the extreme weather

M3 (adaptation measure 3): strengthening/improving production infrastructures to better resilience when exposed to the extreme weather

M4 (adaptation measure 4): improving crop/animal management practices for greater coping capacity of plants/animals under extreme weather conditions

\section{Table 5}

Effects of applying different climate change response measures on mitigating production losses in terms of different CC scenarios by 2030

\begin{tabular}{|c|c|c|c|c|c|c|c|c|c|c|}
\hline \multirow{2}{*}{$\begin{array}{l}\text { Production } \\
\text { affected }\end{array}$} & \multirow{2}{*}{$\begin{array}{l}\text { Extreme } \\
\text { weather }\end{array}$} & \multicolumn{9}{|c|}{$\begin{array}{l}\text { The yield reduction by } 2030 \text { under different climate change } \\
\text { scenarios* ( } \% \text { as compared to the surveyed amount in 2014) }\end{array}$} \\
\hline & & & B1 & & & B2 & & & $\mathrm{A} 2$ & \\
\hline \multicolumn{2}{|c|}{ Response measure } & $\mathrm{M} 0 * *$ & M1 & M2 & M0 & M1 & $\mathrm{M} 2$ & M0 & M1 & M2 \\
\hline
\end{tabular}




\begin{tabular}{|c|c|c|c|c|c|c|c|c|c|c|}
\hline \multirow{2}{*}{$\begin{array}{l}\text { Production } \\
\text { affected }\end{array}$} & \multirow{2}{*}{$\begin{array}{l}\text { Extreme } \\
\text { weather }\end{array}$} & \multicolumn{9}{|c|}{$\begin{array}{l}\text { The yield reduction by } 2030 \text { under different climate change } \\
\text { scenarios* ( } \% \text { as compared to the surveyed amount in 2014) }\end{array}$} \\
\hline & & & B1 & & & B2 & & & $\mathrm{A} 2$ & \\
\hline \multirow{2}{*}{ Rice } & $\begin{array}{l}\text { Prolonged } \\
\text { draught }\end{array}$ & 3.3 & 2.7 & 3.2 & 4.9 & 4.0 & 4.7 & 6.5 & 5.3 & 6.3 \\
\hline & Flooding & 2.6 & 2.1 & 2.5 & 3.9 & 3.2 & 3.8 & 5.2 & 4.2 & 5.0 \\
\hline \multirow{2}{*}{$\begin{array}{l}\text { Fish } \\
\text { farming }\end{array}$} & $\begin{array}{l}\text { Unusual } \\
\text { storms }\end{array}$ & 13.4 & - & 11.1 & 20.1 & - & 16.6 & 28.8 & - & 23.8 \\
\hline & Flooding & 3.3 & - & 2.7 & 4.9 & - & 4.1 & 5.2 & - & 4.3 \\
\hline \multicolumn{2}{|c|}{ Response measure } & M0 & M2 & M3 & M0 & M2 & M3 & M0 & M2 & M3 \\
\hline \multirow{2}{*}{$\begin{array}{l}\text { Shrimp } \\
\text { farming }\end{array}$} & $\begin{array}{l}\text { Unusual } \\
\text { storms }\end{array}$ & 4.2 & 3.8 & 3.9 & 6.3 & 5.7 & 5.9 & 8.4 & 7.6 & 7.9 \\
\hline & $\begin{array}{l}\text { Prolonged } \\
\text { heating }\end{array}$ & 5.8 & 5.3 & 5.4 & 8.7 & 7.9 & 8.2 & 11.6 & 10.5 & 10.9 \\
\hline
\end{tabular}

Notes: * climate change scenarios developed by MONRE (2012)

** no climate change adaptation measures applied

The results of analyzing the impacts of climate change on farmers' poverty vulnerability and the effects of farmers' different adaptation measures to cope with extreme weather events are then incorporated into three main climate change scenarios (B1, B2, A2) ${ }^{3}$ updated by MONRE (2012) along with the overall effects as displayed in Table 5. The results in Table 5 show that proactively applying different climate change response measures contribute significantly to mitigating income losses faced by the farmer households and therefore relaxing their poverty vulnerability. Although the three applied response measures have proved to play a vital role in reducing income losses, the projected income losses under applying different response measures and climate change scenarios by 2030 are still quite large. These results illustrate that the currently applied response measures ${ }^{4}$ have still been far from sufficiency in allowing farmers to 
minimize the negative impacts of climate change on their production and income and thus on their poverty vulnerability.

\section{Conclusion and policy implications}

\subsection{Conclusion}

Climate risks as faced by farmers accounted for proximately $50 \%$ of the income reduction, and the low-income (poorest) group of farmer households is most affected and also most vulnerable to the impacts of climate change and extreme weather events.

The response probability model shows that the impacts of natural disasters and climate change reduce income levels, thereby affecting the accumulation of households ${ }^{*}$ current assets and increasing their poverty vulnerability. This is because when facing risks, farmers either lost their income or had to use parts of their current assets to recover the damages caused by the risks.

Proactive measures to cope with climate change such as changing crops and animal varieties and changing crops and animal cultivating patterns toward more resilience to climate and natural risks should be significantly contributed to mitigating income losses and therefore the poverty vulnerability of farmer households that have been resisting its negative impacts.

Although the currently applied climate change response measures have helped considerably reduce income losses and levels of farmers' poverty vulnerability, the projected income losses under the adaptation of different response measures in the three main climate change scenarios (B1, B2, and A2) in 2030 are still quite large. This illustrates that they have still been far from sufficiency in enabling farmers to minimize the negative influence of climate change on their production and income, and therefore on their poverty vulnerability.

\subsection{Policy implications}

Mekong River Delta has been the most vulnerable to climate change in Vietnam. The results of this research, once again, confirm the appropriateness of the Vietnamese government's strategies to respond to extreme weather events within the region. In order to mitigate the negative impacts of climate change on agricultural production and poverty vulnerability of its farmer inhabitants, the following measures are recommended. 
First, it is necessary to strengthen farmers' coping and resilient capacity to adapt to extreme weather events and therefore to the climate change by assisting them to proactively apply suitable response measures.

Second, although there have currently been effective response measures applied to minimize the production and incomes losses in crop and aquaculture farming, the application scale is still limited and spontaneous among farmer households. There has been a lack of thorough and strategic measures which involve increased integration into regional and local socio-economic development plans for both short and long terms.

Third, the selection of new crop/marine varieties that can tolerate or resist foreseen extreme weathers such as saline water intrusion, flooding, and prolonged draught and heating conditions in order to stand more than ready to cope with them should be one of the most effective measures, given farmers' limited investments and available resources.

Fourth, changing crop patterns or event production systems from three rice crops per year to rice-food crop that requires less water or changing from rice-rice to riceaquaculture (fish or shrimp) systems or complete event to aquaculture farming should be studied carefully in order to propose appropriate solutions to farmers.

Last but not least, applying proactively and combined different effective climate change response measures should always be in production or business plans of farmers as well as planning agenda of the local government in general and the authorities in Mekong River Delta region in particular

\section{Notes}

${ }^{1} 12$ provinces include ex-Ha Tay, Lao Cai, Phu Tho, Dien Bien, Lai Chau, Nghe An, Quang Nam, Khanh Hoa, Dak Lak, Dak Nong, Lam Dong, and Long An.

${ }^{2}$ Following this sampling technique, one province is randomly selected for each sub-region (except for the two provinces selected for the large area of alluvial soils between and along the Tien and Hau Rivers), and likewise for districts and communes. Three villages are randomly selected in each selected commune, and 55 farmers are randomly selected in each village.

${ }^{3}$ Several key climate change scenarios developed and currently updated by MONRE include low emission scenario (B1); intermediate emission scenario (B2, A1B), and high emission scenario (A2, A1FI). 
${ }^{4}$ Three main and significant climate change response measures comprise: (i) changing crop/animal varieties; (ii) changing crop/animal farming patterns; and (iii) improving production infrastructures as defined in Section 3.

\section{References}

Ahmed, S. (2009). Methods in sample surveys. The Johns Hopkins University.

Asian Disaster Preparedness Center. (2003). Climate change and development in Vietnam: Agriculture and Adaptation for the Mekong Delta region. Retrieved from http://www.apangan.net/resource/climate-change-and-development-vietnam-agriculture-and-adaptation-mekongdelta-region

CAP-IPSARD, CIEM, ILSSA. (2013). Characteristic of Vietnamese rural economy - Rural Household Survey in 2012 in 12 provinces. Retrieved from http://www.ciem.org.vn/Portals/1/CIEM/Workplan/2013/VARS_2012_Descriptive_Report_sma 11_file_size.pdf

Chaudhuri, S., Jalan, J., \& Suryahadi, A. (2002). Assessing household vulnerability to poverty: A methodology and estimates for Indonesia (Department of Economics Discussion Paper No. 010252). NY: Columbia University.

Few, R., Viner, D., Bouwer, L. M., Nguyen, H. N., \& Ngo, C. T. (2006). Linking climate change adaptation and disaster risk management for sustainable poverty reduction. Retrieved from http://www2.giz.de/wbf/4tDx9kw63gma/Linking_Climate_Change_Disaster_Risk_Sustainable_ Poverty_Reduction.pdf

Gbetibouo, G. A. (2009). Understanding farmers' perceptions and adaptations to climate change and variability: The case of the Limpopo Basin, South Africa (IFPRI discussion paper 00849). Washington, DC: International Food Policy Research Institute.

GSO. (2011). Results of the Vietnam household living standards survey 2010. Hanoi, Vietnam: Statistical Publishing House.

GSO. (2012). Working labourers over 15 years of age by economic sectors (in Vietnamese). Hanoi, Vietnam: Statistical Publishing House.

GSO. (2013). Statistical yearbook 2013. Hanoi, Vietnam: Statistical Publishing House.

Hadi, A. S. (1992). Identifying multiple outliers in multivariate data. Journal of the Royal Statistical Society. Series B (Methodological), 54(3), 761-771.

Heine, B. (2009). Adaptation to climate change in coastal areas of the Mekong Delta, Vietnam (unpublished paper).

IPSARD. (2013). Characteristics of the Vietnamese rural economy: Evidence from the rural survey in 12 provinces of Vietnam. Hanoi, Vietnam: Statistical Publishing House.

Kuosmanen, T., Post, T., \& Scholtes, S. (2007). Non-parametric tests of productive efficiency with errors-in-variables. Journal of Econometrics, 136(1), 131-162. 
Lasco, R. D., Habito, C. M. D., Delfino, R. J. P., Pulhin, F. B., \& Concepcion, R. M. (2011). Climate change adaptation for smallholder farmers in Southeast Asia. Laguna, Philippines: World Agroforestry Centre.

McElwee, P. (2010). Development and climate change: The social dimensions of adaptation to climate change in Vietnam (WB Discussion Paper Number 17). Washington, DC: The World Bank.

MONRE. (2010). Vietnam's second national communication to the UNFCCC. Hanoi, Vietnam: Ministry of Natural Resources and Environment.

MONRE. (2012). The climate change and sea level rise for Vietnam. Hanoi, Vietnam: Ministry of Natural Resources and Environment.

Neter, J., Wasserman, W., \& Kutner, M. H. (1989). Applied linear regression models (2nd ed.). Homewood, IL: Irwin.

Oxfam International. (2008). Vietnam: Climate change, adaptation and poor people. Oxford, UK: Oxfam International.

Pindyck, R. S., \& Rubinfeld, D. L. (1981). Econometric models and economic forecasts (2nd ed.). NY: McGraw-Hill.

Sheskin, D. (2004). Handbook of parametric and nonparametric statistical procedures (3rd ed.). London, UK: Chapman \& Hall/CRC.

Shuwu, H. T. (2006). Profit efficiency among rice producers in Eastern and Northern Uganda. Kampala, Uganda: Makerere University.

Stata. (2015). Structural equation modeling (SEM). Retrieved January 9, 2016 from http://www.stata.com/stata12/structural-equation-modeling/

The World Bank. (2008). Climate adaptation and development: A strategic framework for the World Bank Group (Technical Report). Retrieved 15 July 2014 from http://siteresources.worldbank.org/ EXTCC/Resources/407863-1219339233881/DCCSFTechnicalReport.pdf.

The World Bank. (2010). The social dimensions of adaptation to climate change in Vietnam. Retrieved from http://documents.worldbank.org/curated/en/2010/12/13431938/socialdimensions-adaptation-climate-change-vietnam

The World Bank and FAO. (2011). Climate change adaptation in agricultural investment in East Asia and the Pacific: Issues and options. Retrieved from http://www.fao.org/docrep/015/i2505e/i2505e00.pdf.

Varian, H. R. (1992). Microeconomic analysis (3rd ed.). NY: Norton.

Vietnamese Government. (2013). Information on Vietnam geography. Retrieved 15 July 2014 from //chinhphu.vn/portal/page/portal/chinhphu/NuocCHXHCNVietNam/ThongTinTongHop/dialy 